\title{
Intraoperative glycemic control in patients undergoing Orthotopic liver transplant: a single center prospective randomized study
}

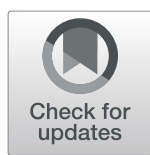

Sathish S. Kumar ${ }^{1 *}$ (D), Shawn J. Pelletier ${ }^{2}$, Amy Shanks ${ }^{1}$, Aleda Thompson ${ }^{1}$, Christopher J. Sonnenday ${ }^{3}$ and Paul Picton ${ }^{1}$

\begin{abstract}
Background: Perioperative hyperglycemia is associated with poor outcomes yet evidence to guide intraoperative goals and treatment modalities during non-cardiac surgery are lacking. End-stage liver disease is associated with altered glucose homeostasis; patients undergoing liver transplantation display huge fluctuations in blood glucose (BG) and represent a population of great interest. Here, we conduct a randomized trial to compare the effects of strict versus conventional glycemic control during orthotopic liver transplant (OLT).

Methods: Following approval by the Institutional Review Board of the University of Michigan Medical School and informed consent, 100 adult patients undergoing OLT were recruited. Patients were randomized to either strict (target BG 80-120 mg/dL) or conventional (target BG 180-200 mg/dL) BG control with block randomization for diabetic and nondiabetic patients. The primary outcomes measured were 1-year patient and graft survival assessed on an intention to treat basis. Graft survival is defined as death or needing re-transplant (www.unos.org). Three and 5 -year patient and graft survival, infectious and biliary complications were measured as secondary outcomes. Data were examined using univariate methods and Kaplan-Meir survival analysis. A sensitivity analysis was performed to compare patients with a mean BG of $\leq 120 \mathrm{mg} / \mathrm{dL}$ and those $>120 \mathrm{mg} / \mathrm{dL}$ regardless of treatment group.
\end{abstract}

Results: There was no statistically significant difference in patient survival between conventional and strict control respectively; 1 year, $88 \%$ vs $88 \%$ ( $p-0.99$ ), 3 years, $86 \%$ vs $84 \%$ ( $p-0.77$ ), 5 years, $82 \%$ vs $78 . \%$ ( $p-0.36$ ). Graft survival was not different between conventional and strict control groups at 1 year, $88 \%$ vs $84 \%$ ( $p-0.56)$ ), 3 years $82 \%$ vs $76 \%$ ( $\mathrm{p}-0.46), 5$ years $78 \%$ vs $70 \%$ ( $\mathrm{p}-0.362)$.

Conclusion: There was no difference in patient or graft survival between intraoperative strict and conventional glycemic control during OLT.

Trial registration: Clinical trial number and registry: www.clinicaltrials.gov NCT00780026. This trial was retrospectively registered on 10/22/2008.

\section{Background}

Perioperative hyperglycemia is associated with poor outcomes including surgical site infections, possibly related to impaired phagocytic function, [1] and increased length of hospital stay. The evidence supporting strict control in critically ill patients was first published almost 16 years ago, [2] but the findings were not

\footnotetext{
* Correspondence: ssathish@med.umich.edu

${ }^{1}$ Department of Anesthesiology, Michigan Medicine, 1H247 UH, 1500 East

Medical Center Drive, SPC 5048, Ann Arbor, MI 48109-5048, USA

Full list of author information is available at the end of the article
}

confirmed within other studies, the results of which suggest a lower risk of death with conventional control rather than strict control $[3,4]$. During cardiac surgery [5] there is a significant reduction in pulmonary, renal complications and death with blood glucose (BG) $<200$ $\mathrm{mg} / \mathrm{dL}$ although there is no improved outcome with strict glucose control (target BG was between 80 and $100 \mathrm{mg} / \mathrm{dl}$ ) [6]. Despite increasing trends towards treating high BG values in the perioperative setting the degree of control remains controversial [7].

(c) The Author(s). 2020 Open Access This article is distributed under the terms of the Creative Commons Attribution 4.0 International License (http://creativecommons.org/licenses/by/4.0/), which permits unrestricted use, distribution, and 
Patients presenting for liver transplantation frequently display insulin resistance, termed hepatogenous diabetes $[8,9]$. In addition, surgical stress, steroids, transfusion and the onset of gluconeogenesis after reperfusion of the new graft result in glucose instability. A retrospective study revealed better outcomes for patients undergoing orthotopic liver transplant (OLT) when the mean intraoperative BG was kept below $150 \mathrm{mg} / \mathrm{dL}$ [10] but prospective studies evaluating BG management during OLT are lacking. Here, we conducted a prospective randomized trial comparing strict versus conventional glucose control for patients undergoing OLT at a single academic medical center. We hypothesized that strict intra-operative blood glucose control improves one-year survival and decreases surgical complications, including infections, following OLT.

\section{Methods}

\section{Study design and patient selection}

Following approval from University of Michigan Medical School Institutional Review Board, Ann Arbor, Michigan (HUM 0016106/HUM 00139554) and written informed consent, adult patients undergoing OLT were randomized to either strict or conventional glycemic control (ClinicalTrials.gov ID: NCT00780026). Block randomization was performed by the study coordinator for diabetic and nondiabetic patients. Subjects were blinded to randomization group but not the clinicians. Post-operative glucose control was directed by the same standard sliding scale protocol used by the intensive care unit for both study groups. This clinical trial is in compliance with CONSORT (Consolidated Standards of Reporting Trials) statement [11].

Adult patients $\geq 18$ years' old who were undergoing liver transplantation were approached for study participation. The exclusion criteria included: Multi-organ transplant recipients, patients receiving an $\mathrm{ABO}$ incompatible liver, HIV infected patients, recipients of an organ from a HIV positive donor, patients who were unable to give informed consent, use of investigational drugs at the time of enrollment or within 30 days or 5 half-lives of enrollment, patients transplanted for hepatocellular carcinoma exceeding 3 nodules or with nodule diameter larger than $5 \mathrm{~cm}$, and a history of malignancy of any organ system treated or untreated within the past 5 years, with the exception of localized basal cell carcinoma of the skin.

All patients received standard induction of anesthesia using fentanyl (1-2 mcg/ $\mathrm{kg}$ ), propofol $(0.5-2 \mathrm{mg} / \mathrm{kg})$, and muscle relaxation using either succinylcholine and/or cisatracurium as deemed appropriate by the anesthesiologist. Anesthesia was maintained with volatile agent. Infusions of cisatracurium for muscle relaxation and fentanyl for analgesia were continued throughout surgery. Methylprednisolone $500 \mathrm{mg}$ was given as a standard immunosuppression to all patients. The use of inotropes and vasopressors were at the discretion of the anesthesiologist and in response to the patient's hemodynamic status. Invasive hemodynamic monitoring included arterial and central venous access for all patients. Transesophageal echocardiography was placed unless contra-indicated by esophageal pathology or difficulty of placement. Pulmonary artery catheters were placed when thought necessary by the anesthesiologist.

\section{Intraoperative blood glucose management}

A dedicated peripheral IV was used for all intravenous insulin administration and infusion tubing was flushed with $20 \mathrm{mls}$ of insulin solution before the tubing was connected directly to the cannula without a carrier. Treatment algorithms were dictated by randomization. BG analysis were performed on arterial blood samples (Gem Premier 3000 ABG analyzer, Instrumentation Laboratory, USA) and repeated every $30 \mathrm{~min}$.

The BG target for intervention in the strict glycemic control group was between 80 and $120 \mathrm{mg} / \mathrm{dL}$. The trigger for treatment was a single BG $>130$ or two $B G>120$ when checked $30 \mathrm{~min}$ apart. Insulin treatment was by intravenous infusion, the rate of which was varied resultant upon glucose level and response to therapy according to the protocol (Table 1).

The BG target for intervention in the conventional control group was $180-200 \mathrm{mg} / \mathrm{dL}$. The trigger for treatment included one value $>200$ or two values $>180 \mathrm{mg} / \mathrm{dL}$ when checked $30 \mathrm{~min}$ apart. Insulin infusion rate was titrated as per protocol. In addition to the continuous intravenous infusion, insulin by intravenous bolus was given if BG > $200 \mathrm{mg} / \mathrm{dL}$ (Table 2).

Hypoglycemia was defined as a single BG $<70 \mathrm{mg} / \mathrm{dL}$ and was treated with $15 \mathrm{~g}$ of $50 \%$ dextrose. BG was evaluated to assess the response to treatment every $15 \mathrm{~min}$ until $\mathrm{BG}>70 \mathrm{mg} / \mathrm{dL}$.

\section{Outcomes}

The primary outcomes were patient and graft survival at 1 year. Graft survival is defined by the United Network for Organ Sharing (www.unos.org) as death or needing retransplant. Secondary outcomes included patient and graft survival at 3 and 5 years, hospital length of stay, biliary and infectious complications (30 days), cardiac, thromboembolic complications, renal failure needing dialysis, reoperation and wound dehiscence at one year.

\section{Statistical analysis}

Basic descriptive statistics were calculated for demographics. Normality of continuous measures was assessed using Kolmogorov-Smirnov test. Pearson Chi-square or Fisher exact tests (for categorical variables) and independent two-tailed t-tests or Mann-Whitney U tests (for continuous variables) were used to assess baseline univariate clinical differences between patients who received strict 
Table 1 Intraoperative glucose management protocol for standard glycemic control

\begin{tabular}{|c|c|c|}
\hline \multicolumn{3}{|c|}{ Insulin Infusion Initiation } \\
\hline $\mathrm{BG}(\mathrm{mg} / \mathrm{dL})$ & $\begin{array}{l}\text { Bolus Regular Insulin } \\
\text { Units IV push }\end{array}$ & $\begin{array}{l}\text { Initial Insulin } \\
\text { Drip Rate Units/hr }\end{array}$ \\
\hline$<180$ & 0 & 0 \\
\hline $181-200$ & 0 & 2 \\
\hline $201-300$ & 3 & 3 \\
\hline$>300$ & 4 & 4 \\
\hline \multicolumn{3}{|c|}{ Insulin Infusion titration } \\
\hline $\mathrm{BG} \mathrm{mg} / \mathrm{dL}$ & $\begin{array}{l}\text { Insulin Infusion (units per hour) } \\
\text { Regular Insulin at Concentration } \\
\text { of } 1 \text { unit/dL }\end{array}$ & \\
\hline$<70$ & $\begin{array}{l}\text { Hold infusion, give } 25 \mathrm{ml} \text { of } 50 \% \\
\text { dextrose IV bolus ( } 1 / 2 \mathrm{vial}) \text {. Re-check } \\
\text { BG every } 15 \text { min until BG }>70 \mathrm{mg} / \mathrm{dL} \text {, } \\
\text { then every } 30 \text { min. When BG }>120 \\
\text { mg/dL restart infusion at } 50 \% \text { of } \\
\text { last rate. }\end{array}$ & \\
\hline 70-79 & $\begin{array}{l}\text { Hold infusion: When } B G>120 \mathrm{mg} / \mathrm{dL} \\
\text { restart infusion at } 50 \% \text { of last rate }\end{array}$ & \\
\hline 80-99 & Decrease infusion by $50 \%$ of last rate & \\
\hline $100-200$ & $\begin{array}{l}\text { Continue current infusion rate unless } \\
\text { BG reduced by }>50 \mathrm{mg} / \mathrm{dl} \text { since last } \\
\text { test, then decrease rate by } 1 \text { unit/hour. }\end{array}$ & \\
\hline $201-250$ & $\begin{array}{l}\text { Increase } 1 \text { unit/hr unless BG reduced } \\
\text { by }>50 \mathrm{mg} / \mathrm{dl} \text { since last test, then } \\
\text { decrease rate by } 1 \text { unit/hour. }\end{array}$ & \\
\hline $251-300$ & $\begin{array}{l}\text { Increase by } 2 \text { units/hour unless BG } \\
\text { reduced by }>50 \mathrm{mg} / \mathrm{dl} \text { since last test, } \\
\text { then decrease rate by } 1 \text { unit/hour. }\end{array}$ & \\
\hline $301-400$ & $\begin{array}{l}\text { Bolus } 4 \text { units regular insulin IV; } \\
\text { increase infusion by } 3 \text { units/hour. }\end{array}$ & \\
\hline$>400$ & $\begin{array}{l}\text { Bolus } 5 \text { units regular insulin IV; } \\
\text { increase infusion by } 4 \text { units/hour }\end{array}$ & \\
\hline
\end{tabular}

Target: $180-200 \mathrm{mg} / \mathrm{dL}$

Trigger: One blood glucose $>200$ or two blood glucoses $>180$ when checked 30 min apart

Hypoglycemia protocol (If blood glucose $<70 \mathrm{mg} / \mathrm{dL}$ ): Hold infusion, give 25 $\mathrm{ml}$ of $50 \%$ dextrose IV bolus $(1 / 2$ vial) and start $50 \mathrm{mls} / \mathrm{hr}$. $10 \%$ glucose. Recheck BG every 15 min until BG $>70 \mathrm{mg} / \mathrm{dL}$, then every $30 \mathrm{~min}$

glucose control and those who received conventional treatment. Survival and graft survival were analyzed using Kaplan Meier curves, with the log rank test for significance on an intention to treat basis.

Analysis was performed using SAS version 9.4 (SAS Institute, Cary, NC) and SPSS version 21.0 (IBM, Somers, NY). Computer-generated randomization was performed using STATA statistical software (StataCorp LP, College Station, Texas). A $p$-value of 0.05 was considered statistically significant.

A sensitivity analysis was performed to compare patients with a mean BG of $\leq 120 \mathrm{mg} / \mathrm{dL}$ and those $>120$ $\mathrm{mg} / \mathrm{dL}$ regardless of randomized group. This cutoff was chosen based on treatment threshold for the strict control group.

\section{Power analysis}

Based on published data [2] the 1-year mortalities for the conventional and strict arms are predicted to be 22 and $9 \%$ respectively. A sample size of 89 has a greater than $80 \%$ power to detect a statistical difference between groups at the $p=0.05$ level. A block randomization for diabetic and non-diabetic patients was used to ensure equal distribution of such patients between the treatment groups.

\section{Results}

Study populations and demographic characteristics

Of the 175 patients screened, 105 patients were consented (two transplants were cancelled before enrollment, two patients were consented but not enrolled at transplant, one patient died during transplantation) and 100 patients completed the study; 50 were randomized to the conventional group and 50 were randomized to the strict glucose control group (Fig. 1). All patients were included for analysis and no patients were lost to follow up. There were no demographic or comorbidity differences between groups (Table 3). Differences in transplant characteristics and surgical factors were not demonstrable between groups (Table 4).

\section{Insulin dose, treatment response and hypoglycemia}

Within the conventional group the mean intraoperative BG was $143.3 \mathrm{mg} / \mathrm{dL}$ [interquartile range (IQR) $123.8 \mathrm{mg} /$ $\mathrm{dL}$ to $167.1 \mathrm{mg} / \mathrm{dL}$ ] and for the strict group $130.7 \mathrm{mg} / \mathrm{dL}$ [IQR $112.2 \mathrm{mg} / \mathrm{dL}$ to $154.8 \mathrm{mg} / \mathrm{dL}](p=0.020$, Table 5$)$. Patients in the strict control group received more insulin (median: 24.4 units [IQR 14.2 to 38.0] vs. 10.0 units [IQR 5.9 to 17.8$], p<0.001)$. Mean BG values over time showed statistically significant difference $(p=0.037)$ between the strict and standard control group with a divergent trajectory following reperfusion of donor graft (Fig. 2). Within the conventional group, seven patients were exposed to at least one hypoglycemic incident; six patients had one episode, one patient had two episodes. Within the strict glucose control group 13 patients exhibited one hypoglycemic episode.

\section{Survival and graft loss}

The primary study (one-year survival) and secondary outcomes for graft and patient (three and five-year survival) are represented in Table 6. Patient survival was not different between conventional and strict groups respectively, (1 year: $88 \%$ vs $88 \%, p=0.999 ; 3$ years: $86 \%$ vs $84 \%, p=0.779 ; 5$ years: $82 \%$ vs $78 \%, p=0.617)$. There was no statistical difference in causes of mortality between the two groups (data not shown). Graft survival was not different between conventional and strict control groups respectively, ( 1 year: $88 \%$ vs $84 \%, p=0.564$; 3 years: $82 \%$ vs $76 \%, p=0.461 ; 5$ years: $78 \%$ vs $70 \%$, $p=0.362$ ). In-hospital graft survival was not statistically 
Table 2 Intraoperative glucose management protocol for strict glycemic control

\begin{tabular}{|c|c|c|c|c|c|}
\hline \multicolumn{2}{|l|}{ Column 1† } & \multicolumn{2}{|l|}{ Column 2f } & \multicolumn{2}{|l|}{ Column $3 \S$} \\
\hline $\begin{array}{l}\text { Serum Glucose } \\
\text { Level, mg/dL }\end{array}$ & $\begin{array}{l}\text { Insulin Infusion Rate, U/ } \\
\mathrm{h}\end{array}$ & $\begin{array}{l}\text { Serum Glucose Level, m/ } \\
\mathrm{dL}\end{array}$ & $\begin{array}{l}\text { Insulin Infusion Rate, U/ } \\
\text { h }\end{array}$ & $\begin{array}{l}\text { Serum Glucose Level, mg/ } \\
\mathrm{dL}\end{array}$ & $\begin{array}{l}\text { Insulin Infusion Rate, U/ } \\
\text { h }\end{array}$ \\
\hline$>400$ & 18 & $>400$ & 25 & $>400$ & 30 \\
\hline $351-400$ & 16 & $351-400$ & 22 & $351-400$ & 27 \\
\hline $301-350$ & 14 & $301-350$ & 20 & $301-350$ & 24 \\
\hline $251-300$ & 12 & $251-300$ & 18 & $251-300$ & 21 \\
\hline $201-250$ & 10 & $201-250$ & 15 & $201-250$ & 18 \\
\hline $176-200$ & 8 & $176-200$ & 12 & $176-200$ & 15 \\
\hline $151-175$ & 6 & $151-175$ & 9 & $151-175$ & 12 \\
\hline $121-150$ & 4 & $121-150$ & 7 & $121-150$ & 9 \\
\hline $101-120$ & 2 & $101-120$ & 4 & $101-120$ & 6 \\
\hline 80-100 & 1 & 80-100 & 2 & 80-100 & 3 \\
\hline$<80$ & Off & $<80$ & Off & $<80$ & Off \\
\hline
\end{tabular}

${ }^{1}$ When glucose level is $<80 \mathrm{mg} / \mathrm{dL}$, stop insulin infusion and initiate $50 \mathrm{~mL} / \mathrm{h}$ of $10 \%$ dextrose infusion. Check glucose every 30 min until glucose level is $\geq 80 \mathrm{mg} /$ $\mathrm{dL}$ - Discontinue $10 \%$ dextrose infusion. Resume insulin infusion, always in column 1. If glucose level is $<70 \mathrm{mg} / \mathrm{dL}$, initiate treatment of hypoglycemia protocol. Restart insulin infusion in column 1 when glucose level $\geq 80 \mathrm{mg} / \mathrm{dL}$

† Start in this column; restart in this column when insulin infusion has to be discontinued for glucose level $<80 \mathrm{mg} / \mathrm{dL}$

\# Patient has not reached glucose level range of $80-110 \mathrm{mg} / \mathrm{dL}$ within $2 \mathrm{~h}$ of using column 1 and glucose level has decreased by $<50 \mathrm{mg} / \mathrm{dL}$ over preceding $1 \mathrm{~h}$ $\S$ Patient had not reached glucose level range of $80-110 \mathrm{mg} / \mathrm{dL}$ within $2 \mathrm{~h}$ of using column 2 and glucose level has decreased by $<50 \mathrm{mg} / \mathrm{dL}$ over preceding $1 \mathrm{~h}$ Target: $80-120 \mathrm{mg} / \mathrm{dL}$

Trigger: One blood glucose $>130$ or two blood glucoses $>120$ when checked $30 \mathrm{~min}$ apart. Bolus doses should not be necessary using this protocol Hypoglycemia protocol (If blood glucose $<70 \mathrm{mg} / \mathrm{dL}$ ): Hold infusion, give $25 \mathrm{ml}$ of $50 \%$ dextrose IV bolus (1/2 vial) and start $50 \mathrm{mls} / \mathrm{hr}$. 10\% glucose. Re-check BG every $15 \mathrm{~min}$ until $\mathrm{BG}>70 \mathrm{mg} / \mathrm{dL}$, then every $30 \mathrm{~min}$

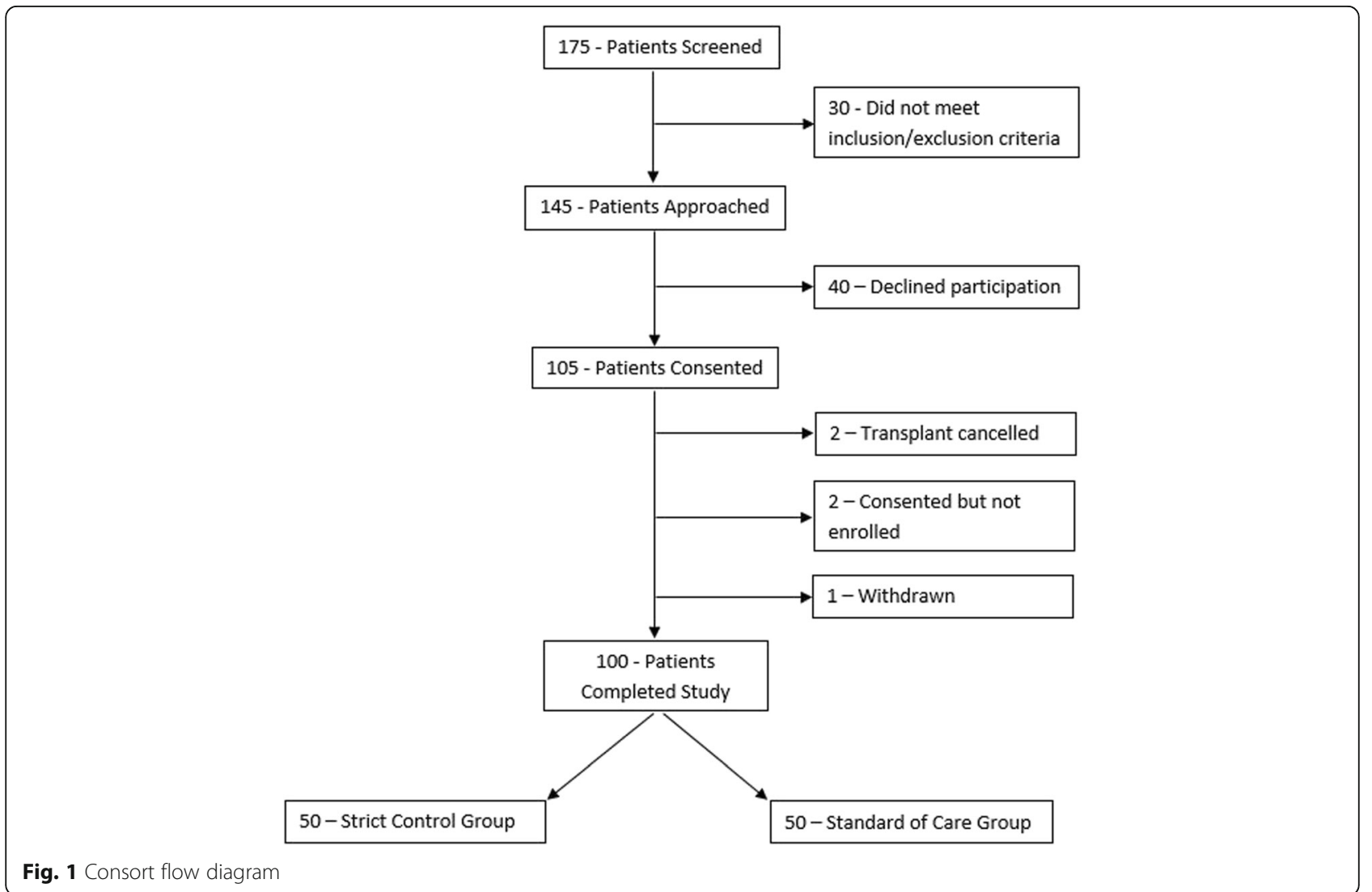

Fig. 1 Consort flow diagram 
Table 3 Population and Baseline Characteristics

\begin{tabular}{|c|c|c|c|}
\hline & Current Standard of Care $(N=50)$ & Strict Glucose Control $(N=50)$ & P-Value \\
\hline \multicolumn{4}{|l|}{ Patient Demographics } \\
\hline Age & $55.0[50.0$ to 59.0$]$ & $54.0[48.0$ to 57.0$]$ & 0.201 \\
\hline Race & & & 0.580 \\
\hline White & $41(82.0)$ & $41(82.0)$ & \\
\hline African American & $4(8.0)$ & $5(10.0)$ & \\
\hline Asian & $1(2.0)$ & $0(0.0)$ & \\
\hline Other & $4(8.0)$ & $4(8.0)$ & \\
\hline WHO BMI Classification & & & 0.415 \\
\hline Underweight & $0(0.0)$ & $0(0.0)$ & \\
\hline Normal & $12(24.5)$ & $10(20.0)$ & \\
\hline Overweight & $18(36.7)$ & $14(28.0)$ & \\
\hline Obese & 19 (38.8) & $26(52.0)$ & \\
\hline Female Sex & $14(28.0)$ & $12(24.0)$ & 0.648 \\
\hline \multicolumn{4}{|l|}{ Pre-Existing Conditions } \\
\hline Diabetes & $16(32.0)$ & $13(26.0)$ & 0.509 \\
\hline CAD & $4(8.0)$ & $4(8.0)$ & 0.999 \\
\hline MELD Score & $20.5[15.0$ to 23.0$]$ & $19.5[12.5$ to 25.5$]$ & 0.744 \\
\hline \multicolumn{4}{|l|}{ Cause of Liver Disease' } \\
\hline Alagille's Syndrome & $0(0.0)$ & $2(4.0)$ & 0.495 \\
\hline Alpha-1 Antitrypsin Deficiency & $4(8.0)$ & $0(0.0)$ & 0.118 \\
\hline Hepatocellular Carcinoma (non-Fibrolamellar) & $13(26.0)$ & $19(38.0)$ & 0.198 \\
\hline Alcohol-related Cirrhosis & $18(36.0)$ & $12(24.0)$ & 0.190 \\
\hline Cryptogenic Cirrhosis & $4(8.0)$ & $5(10.0)$ & 0.999 \\
\hline Primary Biliary Cirrhosis & $2(4.0)$ & $1(2.0)$ & 0.999 \\
\hline Secondary Biliary Cirrhosis & $1(2.0)$ & $0(0.0)$ & 0.999 \\
\hline Cystic Fibrosis & $1(2.0)$ & $0(0.0)$ & 0.999 \\
\hline Hemochromatosis & $1(2.0)$ & $0(0.0)$ & 0.999 \\
\hline Hepatitis C, Chronic & $18(36.0)$ & $18(36.0)$ & 0.999 \\
\hline Hepatitis, Chronic Active & $2(4.0)$ & $3(6.0)$ & 0.999 \\
\hline Hepatic Failure (Idiopathic) & $1(2.0)$ & $0(0.0)$ & 0.999 \\
\hline $\mathrm{HCC}$ & $1(2.0)$ & $1(2.0)$ & 0.999 \\
\hline Hypertensive Nephrosclerosis & $1(2.0)$ & $0(0.0)$ & 0.999 \\
\hline Polycystic Liver Disease & $1(2.0)$ & $0(0.0)$ & 0.999 \\
\hline Non-Alcoholic Steatohepatitis & $2(4.0)$ & $4(8.0)$ & 0.678 \\
\hline Primary Sclerosing Cholangitis & $5(10.0)$ & $8(16.0)$ & 0.554 \\
\hline Unknown & $1(2.0)$ & $1(2.0)$ & 0.999 \\
\hline Wilson's Disease & $0(0.0)$ & $1(2.0)$ & 0.999 \\
\hline
\end{tabular}

${ }^{1}$ Cause of liver disease is not mutually exclusive. Data are presented as frequency (\%) or median [25th percentile to 75 th percentile], as appropriate

significant between treatment groups $(p=0.118)$. Kaplan-Meier 5-year survival rate not reveal any statistically significant difference between the two groups $(p=0.490$, Fig. 3a). Fig. 3b shows the same trend for the 5 -year graft survival rate $(p=0.303)$. There was no difference in postoperative ICU stay between groups (median: 3.0 days [IQR 2.0 to 5.0 for both]; $p=0.934$ ).
Biliary, infectious and other complications

Despite some clinically significant differences between the treatment groups, there were no statistically significant differences between the strict and conventional group for any secondary outcome measures which included bile leak $(p=0.826)$, re-operation for bleeding $(p=0.275)$, renal failure needing dialysis $(p=0.401)$, bacterial infection 
Table 4 Transplant characteristics, surgical factors, and post-surgical complications

\begin{tabular}{|c|c|c|c|}
\hline & Current standard of care $(N=50)$ & Strict glucose control $(N=50)$ & P-Value \\
\hline \multicolumn{4}{|c|}{ Transplant Characteristics and Surgical Factors } \\
\hline High Risk Donor & $5(10.0)$ & $7(14.0)$ & 0.538 \\
\hline Warm Ischemic Time (Minutes) & $26.0[23.0$ to 32.0$]$ & $27.0[23.0$ to 33.0$]$ & 0.916 \\
\hline Cold Ischemic Time (Minutes) & $400.0[323.0$ to 488.0$]$ & $385.5[333.0$ to 429.0$]$ & 0.572 \\
\hline Total Ischemic Time (Minutes) & $431.0[354.0$ to 522.0$]$ & $415.5[367.0$ to 455.0$]$ & 0.575 \\
\hline Total Surgical Time (Minutes) & $313.0[281.0$ to 369.0$]$ & $329.9[307.0$ to 375.8$]$ & 0.228 \\
\hline \multicolumn{4}{|l|}{ Intraoperative Blood Product Usage } \\
\hline Packed red cells (mL) & $2450.0[1050.0$ to 3850.0$]$ & $2450.0[1400.0$ to 3500.0$]$ & 0.475 \\
\hline Platelets (mL) & $500.0[500.0$ to 750.0$]$ & $625.0[375.0$ to 750.0$]$ & 0.667 \\
\hline Cryoprecipitate (mL) & 200.0 [100.0 to 200.0] & $200.0[100.0$ to 400.0$]$ & 0.438 \\
\hline Cell Saver (mL) & $999.0[500.0$ to 1425.0$]$ & $848.0[700.0$ to 1600.0$]$ & 0.645 \\
\hline
\end{tabular}

Data are presented as frequency (\%) or median [25th percentile to 75 th percentile], as needed

( $p=0.841)$, fungal infection $(p=0.298)$, wound infection $(p=0.585)$ and viral infection $(p=0.505)$ (Table 6).

\section{Sensitivity analysis}

A sensitivity analysis was performed to compare patients with a mean BG of $\leq 120 \mathrm{mg} / \mathrm{dL}$ and those $>120 \mathrm{mg} / \mathrm{dL}$, regardless of treatment group, to assess the response to insulin treatment or insulin resistance. The sensitivity analysis included all 100 patients; of those with BG < $120 \mathrm{mg} / \mathrm{dL}, 19(70.4 \%)$ were from the strict control group and 8 (29.6\%) were from the conventional group. There was statistically significant improved survival for patients with a mean intraoperative $B G$ of $\leq 120 \mathrm{mg} / \mathrm{dL}$ with a $\log$ rank $p$ value of 0.047 (Fig. 4).

After adjustment for patient comorbidities, chronic preoperative steroid use, and intraoperative transfusion using a multivariable Cox proportional hazard model, blood glucose $\leq 120 \mathrm{mg} / \mathrm{dL}$ did not show any significant difference in survival.

\section{Discussion}

We report the first randomized study directly comparing strict versus conventional glucose control during the intraoperative period of liver transplantation with comprehensive long term follow up. We found no difference in patient or graft survival after OLT between the conventional and strict glucose control regimens when analyzed on an intention to treat basis. However, the sensitivity analysis revealed improved survival for those patients with a mean blood glucose $\leq 120 \mathrm{mg} / \mathrm{dL}$ regardless of treatment group, perhaps identifying a group of 'responders' or implying the requirement for more aggressive insulin management than that used within our strict control group.

Although patients in the strict group received greater than twice the dose of insulin and exhibited an approximate $10 \%$ reduction in mean intraoperative blood glucose when compared to the conventional group; these differences may not have been large enough to produce a clinically significant difference in the outcomes measured. However, most divergence in blood glucose between groups can be appreciated only after reperfusion perhaps illustrating that reliance on differences in the mean of the total operative time to be limited. The strict glucose regimen was modified from the landmark NICE-SUGAR trial, [12] the most aggressive regimen published to date, and associated with a $7 \%$ incidence of severe hypoglycemia $(<40 \mathrm{mg} / \mathrm{dL})$. Within the conventional group, 7 patients were exposed to at least one hypoglycemic incident; 6 patients had one episode, 1 patient had two episodes. Within the strict glucose control group 13 patients exhibited 1 hypoglycemic episode. Numerically, hypoglycemic

Table 5 Glucose control

\begin{tabular}{lllr}
\hline & Current standard of care $(N=50)$ & Strict glucose control $(N=50)$ & \\
\hline Total No. of Hypoglycemia Incidents & & & \\
0 & $43(86.0)$ & $174.0)$ & 0.125 \\
1 & $6(12.0)$ & $0(0.0)$ & $13(26.0)$ \\
2 & $1(2.0)$ & $24.4[14.2$ to 38.0$]$ & 0.134 \\
Hypoglycemia at any time & $7(14.0)$ & $130.7[112.2$ to 154.8$]$ &
\end{tabular}

Data are presented as frequency (\%) or median [25th percentile to 75 th percentile], as needed 


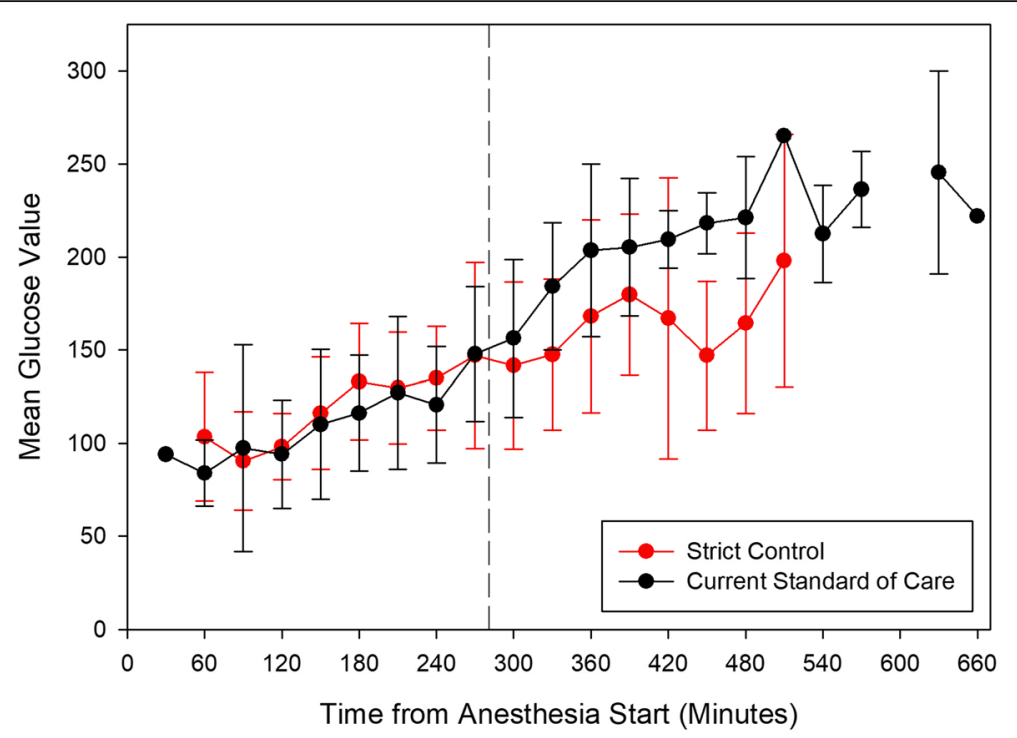

Fig. 2 Mean intraoperative blood glucose with 95\% confidence intervals for standard and strict glycemic control groups. The vertical dashed line represents the median revascularization time, which was similar in both groups

episodes were higher in the strict control group although there was no statistically significant difference between the number of patients exposed to hypoglycemia or the total number of hypoglycemic episodes between groups. The routine provision of abundant anesthesia resources for liver transplantation allowed for frequent glucose monitoring and rapid intervention for changes in plasma glucose when detected and may enhance safety for aggressive glucose management in this patient population. Patients undergoing liver transplant have the potential to exhibit hyperglycemia due to insulin resistance [9] and the exogenous administration of steroids may make hypoglycemia less likely; it appears that aggressive insulin therapy is not associated with a greater risk of hypoglycemia compared to conventional control and can be managed safely during the intraoperative phase of liver transplantation.

We found a statistically significant difference in patient survival if mean BG was less than $120 \mathrm{mg} / \mathrm{dl}$ in the sensitivity analysis although the adjusted analysis did not show any significant difference A recent prospective study investigated postoperative glycemic control and impact on outcomes at one year following liver transplantation and revealed a reduced incidence of infection with BG levels of $140 \mathrm{mg} / \mathrm{dl}$ but a higher incidence of moderate hypoglycemia $(41-70 \mathrm{mg} / \mathrm{dl})$ was described [13]. We did not continue randomization into the postoperative period but doing so as well as monitoring all elements of glucose control throughout the first postoperative year are likely of critical importance for the outcomes measured and represent a design flaw within this study.

Hyperglycemia is associated with a spectrum of poor outcomes including poor graft survival [14] and in animal studies is associated with defective handling of calcium in cardiac myocytes resulting in poor cardiac function [15]. Insulin treatment appears to reduce afterload and improve ventricular relaxation although changes in myocardial perfusion or contractility have not been demonstrated [16]. Treatment of hyperglycemia, especially in patients with non-insulin dependent DM, has been shown to improve immune function, hypercoagulability and possibly reduce the risk of infectious complications [1]; it is postulated that hyperglycemia results in impaired phagocytosis secondary to high intra-cellular calcium concentrations. In addition to hepatgeneous diabetes, immunosuppression with steroids and stress hyperglycemia likely contribute to profound fluctuations in BG levels during liver transplantation $[8,17,18]$. It is interesting to note that we found no differences in infectious complications between groups here. The precise mechanism of stress induced hyperglycemia is not clear but it is associated with poor post-operative outcomes following non-cardiac surgery [19]. Insulin resistance is likely a primary factor and general anesthesia per se may be contributory; a recent animal study reveals an increase in insulin resistance by almost $50 \%$ and insulin effects at the liver were almost completely suppressed [20]. Liver transplantation is associated with potential for significant blood loss and transfusion. Citrate phosphate dextrose (CPD) preservative solutions contribute to serum glucose; there was no difference in transfusion requirements between treatment groups.

Despite decades of research conducted within the intensive care setting glucose control remains controversial and strict control is currently not recommended for critically ill patients [21]. The thresholds to treat hyperglycemia in the cardiac surgical population may be lower compared to non-cardiac surgical patients potentially related to the 
Table 6 Post-surgical complications

\begin{tabular}{|c|c|c|c|}
\hline & Current standard of care $(N=50)$ & Strict glucose control $(N=50)$ & P-Value \\
\hline \multicolumn{4}{|l|}{ Survival Outcomes } \\
\hline Graft Loss & $11(22.0)$ & $16(32.0)$ & 0.260 \\
\hline Death & $9(18.0)$ & $12(24.0)$ & 0.461 \\
\hline \multicolumn{4}{|l|}{ Overall Survival } \\
\hline 30 Day Survival & $49(98.0)$ & $49(98.0)$ & 0.999 \\
\hline 1 Year Survival & $44(88.0)$ & $44(88.0)$ & 0.999 \\
\hline 3 Year Survival & $43(86.0)$ & $42(84.0)$ & 0.779 \\
\hline 5 Year Survival & $41(82.0)$ & $39(78.0)$ & 0.617 \\
\hline \multicolumn{4}{|l|}{ Graft Survival } \\
\hline 30 Day Graft Survival & $48(96.0)$ & $49(98.0)$ & 0.999 \\
\hline 1 Year Graft Survival & $44(88.0)$ & $42(84.0)$ & 0.564 \\
\hline 3 Years Graft Survival & $41(82.0)$ & $38(76.0)$ & 0.461 \\
\hline 5 Years Graft Survival & $39(78.0)$ & $35(70.0)$ & 0.362 \\
\hline \multicolumn{4}{|l|}{ Complications } \\
\hline Bile Leak & $15(30.0)$ & $14(28.0)$ & 0.826 \\
\hline Biliary Stricture & $20(40.0)$ & $13(26.0)$ & 0.137 \\
\hline CVA & $1(2.0)$ & $0(0.0)$ & 0.999 \\
\hline Hepatic Arterial Stricture & $3(6.0)$ & $1(2.0)$ & 0.617 \\
\hline Major Cardiac Event & $5(10.0)$ & $4(8.0)$ & 0.999 \\
\hline Portal Vein Thrombosis & $3(6.0)$ & $3(6.0)$ & 0.999 \\
\hline Re-operation: Bleeding & $6(12.0)$ & $10(20.0)$ & 0.275 \\
\hline Re-operation: Other & $9(18.0)$ & $15(30.0)$ & 0.160 \\
\hline Renal Failure - Dialysis & $9(18.0)$ & $6(12.0)$ & 0.401 \\
\hline Wound Dehiscence & $5(10.0)$ & $12(24.0)$ & 0.062 \\
\hline \multicolumn{4}{|l|}{ Infections } \\
\hline Bacterial & $26(52.0)$ & $27(54.0)$ & 0.841 \\
\hline Fungal & $7(14.0)$ & $11(22.0)$ & 0.298 \\
\hline Transplant Incision Wound & $7(14.0)$ & $9(18.0)$ & 0.585 \\
\hline Viral & $6(12.0)$ & $4(8.0)$ & 0.505 \\
\hline \multicolumn{4}{|l|}{ Hospital Outcomes } \\
\hline Length of Stay (days) & $11.0[8.0$ to 19.0$]$ & $12.5[8.0$ to 19.0$]$ & 0.384 \\
\hline
\end{tabular}

Data are presented as frequency (\%) or median [25th percentile to 75 th percentile], as needed

effects of metabolic syndrome and hyperglycemia during cardiopulmonary bypass [22]. It is possible that patients undergoing liver transplantation share similarity with cardiac surgical patients as signaled by the results of our sensitivity analysis. There is a lack of robust data from the perioperative setting in the non-cardiac surgical patients. Our current practice is mostly based upon retrospective investigations which suggests $B G>200 \mathrm{mg} / \mathrm{dL}$ is associated with poor outcomes [23, 24]. Any improved outcome implied from our sensitivity analysis may not only impact OLT but may be of broader significance for other noncardiac surgical patients as there is lack of good evidence in defining treatment strategies As implied by our data, it is possible to implement tight control safely with careful monitoring of BG during the intraoperative phase of an OLT [25]. Outcome differences in perioperative glycemic control may not be solely related to glycemic control per se, but may also be attributed to differences in the level of supervision, accuracy of monitoring, clinical setting and infusion practices [26].

Previous studies have reported that glucose variability was associated with acute kidney injury following OLT $[24,27,28]$ which was not related directly to hyperglycemia or hypoglycemia. However, this study did not detect a difference in the requirement for dialysis postoperatively between groups but we did not measure 

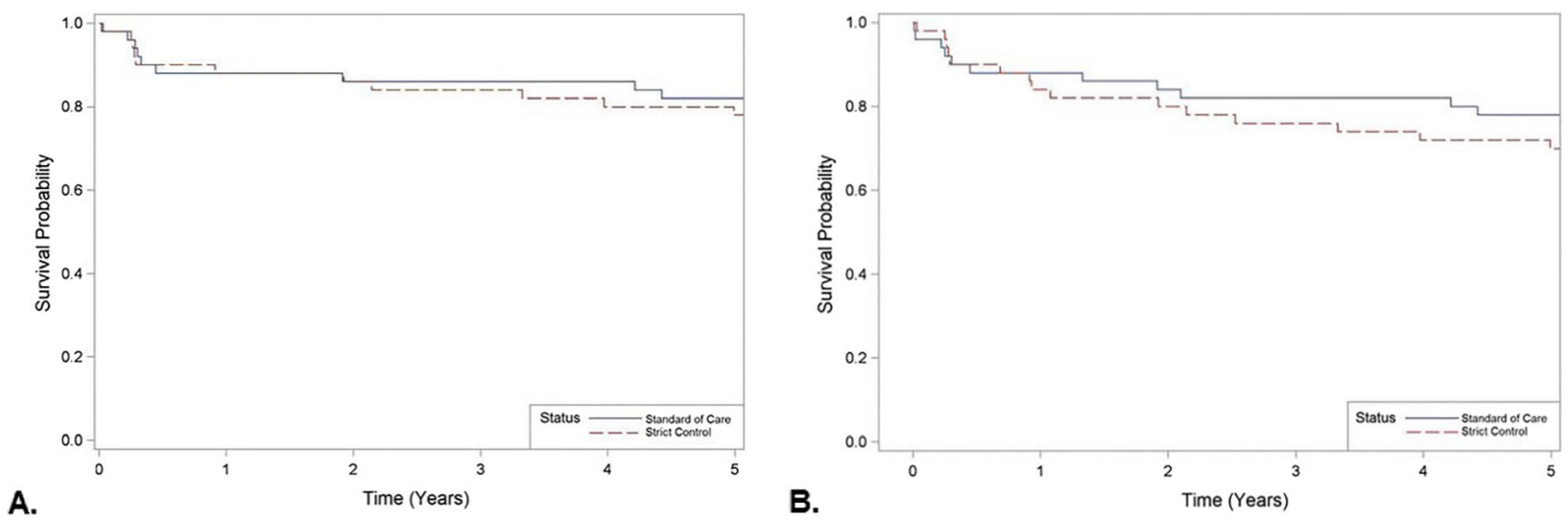

Fig. 3 Overall survival for standard and strict glycemic control groups with time along the $X$-axis and survival probability along the $Y$-axis. A) Fiveyear mortality, log- rank test $p=0.490$. B) Five-year graft survival log-rank test $p=0.303$

glucose variability. In terms of detecting glucose variability, technological advances for continuous glucose monitoring and real time alerting systems may be helpful in achieving stability of BG [29, 30]. Intravenous insulin infusions have advantage over [31] subcutaneous bolus or the widely used sliding scale in maintaining steady state to prevent glucose variability [32-34].

There are limitations with our study. The sample size was small and the study population was heterogeneous. We did not achieve the target BG in the strict group, despite the use of an aggressive insulin protocol, potentially related to insulin resistance seen in patients with liver disease and the measurable difference in BG between groups may have been of insufficient magnitude to result in a meaningful clinical difference between groups. Although current evidence does not recommend strict control in the perioperative period, our strict control group was defined based on the existing literature at the time of study initiation. However, the statistically significant difference in the intraoperative BG level between groups diverged as the case progressed. The study focused exclusively on intraoperative glycemic control; including the immediate postoperative phase would have been a major improvement in study design. However, differences in patient survival following liver transplant are associated with intraoperative BG control [10] and a large retrospective study in non-cardiac surgery found that a higher mean intraoperative BG increased the odds for higher postoperative BG, [35] implying that control of the intraoperative phase of care is a rational research question. In addition, poor glycemic control in the intraoperative period adversely impacts outcome [5, 36, 37] yet the influence of postoperative management cannot be underestimated [35]. Lastly, we did not evaluate glucose

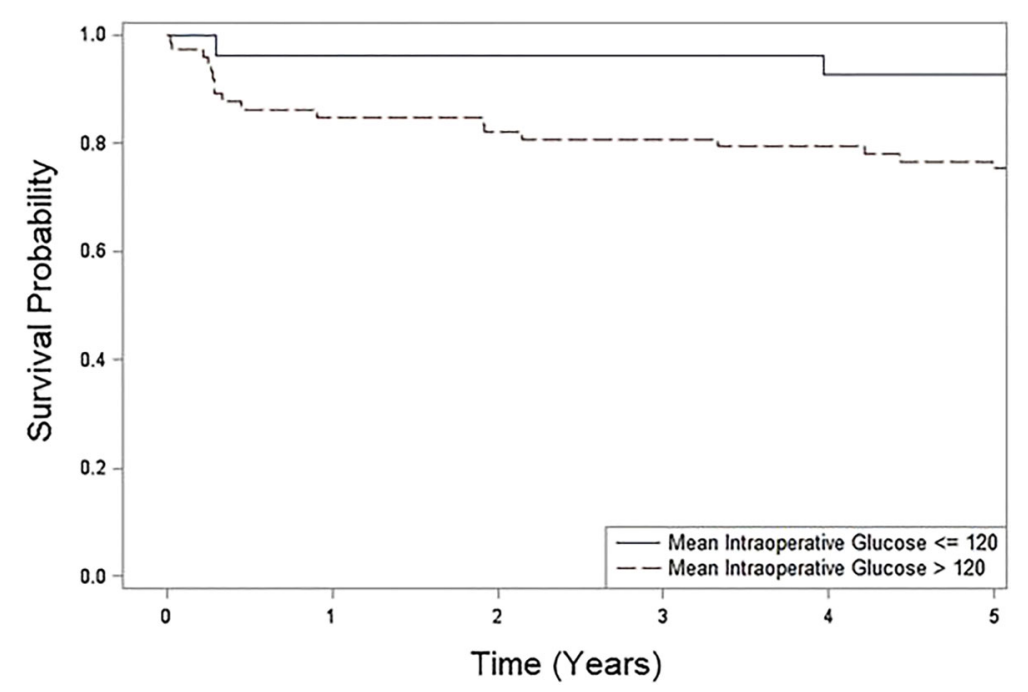

Fig. 4 Overall 5-year patient survival comparing patients with mean blood glucose less than or equal to $120 \mathrm{mg} / \mathrm{dL}$ to those with a mean blood glucose greater than $120 \mathrm{mg} / \mathrm{dL}$ with time along $\mathrm{X}$-axis and survival probability along Y-axis. The log-rank test $p=0.047$ 
homeostasis in donors but improved recipient outcome has been achieved with improved glycemic control in donors [38]. A direct relationship between donor and recipient glucose variability may exist and be an unmeasured confounder within this study.

\section{Conclusion}

In conclusion, there is no patient or graft survival advantage with strict glucose management compared to conventional glucose management during the intraoperative phase for patients undergoing liver transplantation when evaluated on an intention to treat basis.

\section{Abbreviations}

BG: Blood glucose; OLT: Orthotopic liver transplant

\section{Acknowledgements \\ Not Applicable.}

\section{Consent for publicaton}

Not Applicable.

\section{Authors' contributions}

SK- Manuscript preparation, data analysis. SP- Research design, participation of research. AS- Research design, data analysis, manuscript revision. AT- Data analysis. CS- Data acquisition and manuscript revision. PP- Research design, performance of the research, data analysis, manuscript preparation and revision. All authors read and approved the final manuscript.

\section{Funding}

This research received funding from the Michigan Institute for Clinical \& Health Research (MICHR), which is supported by a grant from the National Center for Advancing Translational Sciences (NCATS) (UL1TR000433) - SJP and PP. The funding bodies played no role in the design of the study and collection, analysis, and interpretation of data and in writing the manuscript".

\section{Availability of data and materials}

The datasets used and/or analysed during the current study are available only after de-identification from the corresponding author on reasonable request.

\section{Ethics approval and consent to participate}

Following approval from University of Michigan Medical School Institutional Review Board, Ann Arbor, Michigan (HUM 0016106/HUM 00139554) and written informed consent, adult patients undergoing OLT were randomized to either strict or conventional glycemic control (ClinicalTrials.gov ID: NCT00780026). This clinical trial is in compliance with CONSORT statement.

\section{Competing interests}

The authors declare no conflict of interest.

\section{Author details}

'Department of Anesthesiology, Michigan Medicine, 1H247 UH, 1500 East Medical Center Drive, SPC 5048, Ann Arbor, MI 48109-5048, USA. ${ }^{2}$ University of Virginia, 1215 Lee st, Charlottesville, VA 22908, USA. ${ }^{3}$ Department of surgery, Michigan Medicine, Ann Arbor, MI, USA.

Received: 2 June 2019 Accepted: 23 December 2019

Published online: 04 January 2020

\section{References}

1. Alexiewicz JM, Kumar D, Smogorzewski M, Klin M, Massry SG. Polymorphonuclear leukocytes in non-insulin-dependent diabetes mellitus: abnormalities in metabolism and function. Ann Intern Med. 1995;123(12):919-24.

2. van den Berghe $G$, Wouters $P$, Weekers F, Verwaest $C$, Bruyninckx F, Schetz M, Vlasselaers D, Ferdinande P, Lauwers P, Bouillon R. Intensive insulin therapy in critically ill patients. N Engl J Med. 2001;345(19):1359-67.

3. Preiser JC. NICE-SUGAR: the end of a sweet dream? Crit Care. 2009;13(3):143.
4. Preiser JC, Devos P, Ruiz-Santana S, Melot C, Annane D, Groeneveld J, lapichino $G$, Leverve $X$, Nitenberg $G$, Singer $P$, et al. A prospective randomised multi-Centre controlled trial on tight glucose control by intensive insulin therapy in adult intensive care units: the Glucontrol study. Intensive Care Med. 2009;35(10):1738-48.

5. Gandhi GY, Nuttall GA, Abel MD, Mullany CJ, Schaff HV, Williams BA, Schrader LM, Rizza RA, McMahon MM. Intraoperative hyperglycemia and perioperative outcomes in cardiac surgery patients. Mayo Clin Proc. 2005;80(7):862-6.

6. Gandhi GY, Nuttall GA, Abel MD, Mullany CJ, Schaff HV, O'Brien PC, Johnson MG, Williams AR, Cutshall SM, Mundy LM, et al. Intensive intraoperative insulin therapy versus conventional glucose management during cardiac surgery: a randomized trial. Ann Intern Med. 2007;146(4):233-43.

7. Duggan EW, Carlson K, Umpierrez GE. Perioperative hyperglycemia management: an update. Anesthesiology. 2017;126(3):547-60.

8. Garcia-Compean D, Jaquez-Quintana JO, Maldonado-Garza H. Hepatogenous diabetes. Current views of an ancient problem. Ann Hepatol. 2009;8(1):13-20.

9. Park CS. Predictive roles of intraoperative blood glucose for post-transplant outcomes in liver transplantation. World J Gastroenterol. 2015;21(22):6835-41.

10. Ammori JB, Sigakis M, Englesbe MJ, O'Reilly M, Pelletier SJ. Effect of intraoperative hyperglycemia during liver transplantation. J Surg Res. 2007; 140(2):227-33.

11. Todd MM. Clinical research manuscripts in anesthesiology. Anesthesiology. 2001;95(5):1051-3

12. Investigators N-SS, Finfer S, Chittock DR, Su SY, Blair D, Foster D, Dhingra V, Bellomo R, Cook D, Dodek P, et al. Intensive versus conventional glucose control in critically ill patients. N Engl J Med. 2009;360(13):1283-97.

13. Wallia A, Schmidt K, Oakes DJ, Pollack T, Welsh N, Kling-Colson S, Gupta S, Fulkerson C, Aleppo G, Parikh N, et al. Glycemic control reduces infections in post-liver transplant patients: results of a prospective, Randomized Study. J Clin Endocrinol Metab. 2017;102(2):451-9.

14. Maamoun HA, Soliman AR, Fathy A, Elkhatib M, Shaheen N. Diabetes mellitus as predictor of patient and graft survival after kidney transplantation. Transplant Proc. 2013;45(9):3245-8.

15. Sorrentino A, Borghetti G, Zhou Y, Cannata A, Meo M, Signore S, Anversa P, Leri A, Goichberg P, Qanud K, et al. Hyperglycemia induces defective Ca2+ homeostasis in cardiomyocytes. Am J Physiol Heart Circ Physiol. 2017;312(1): H150-61.

16. Boly CA, Eringa EC, Bouwman RA, van den Akker RF, de Man FS, Schalij I, Loer SA, Boer C, van den Brom CE. The effect of perioperative insulin treatment on cardiodepression in mild adiposity in mice. Cardiovasc Diabetol. 2016;15(1):135.

17. Low Y, White WD, Habib AS. Postoperative hyperglycemia after 4- vs 8-10mg dexamethasone for postoperative nausea and vomiting prophylaxis in patients with type II diabetes mellitus: a retrospective database analysis. J Clin Anesth. 2015;27(7):589-94.

18. Palermo NE, Gianchandani RY, McDonnell ME, Alexanian SM. Stress hyperglycemia during surgery and anesthesia: pathogenesis and clinical implications. Curr Diab Rep. 2016;16(3):33.

19. Kotagal M, Symons RG, Hirsch IB, Umpierrez GE, Dellinger EP, Farrokhi ET, Flum DR, Collaborative S-C. Perioperative hyperglycemia and risk of adverse events among patients with and without diabetes. Ann Surg. 2015;261(1):97-103.

20. Kim SP, Broussard JL, Kolka CM. Isoflurane and Sevoflurane induce severe hepatic insulin resistance in a canine model. PLoS One. 2016:11(11): e0163275.

21. Lipshutz AK, Gropper MA. Perioperative glycemic control: an evidencebased review. Anesthesiology. 2009;110(2):408-21.

22. Donatelli F, Cavagna P, Di Dedda G, Catenacci A, Di Nicola M, Lorini L, Fumagalli R, Carli F. Correlation between pre-operative metabolic syndrome and persistent blood glucose elevation during cardiac surgery in nondiabetic patients. Acta Anaesthesiol Scand. 2008;52(8):1103-10.

23. Akhtar S, Barash PG, Inzucchi SE. Scientific principles and clinical implications of perioperative glucose regulation and control. Anesth Analg. 2010;110(2):478-97.

24. Dhatariya K, Levy N, Hall GM. The impact of glycaemic variability on the surgical patient. Curr Opin Anaesthesiol. 2016;29(3):430-7.

25. Schultz MJ, Harmsen RE, Korevaar JC, Abu-Hanna A, Van Braam HF, Van Der Sluijs JP, Spronk PE. Adoption and implementation of the original strict glycemic control guideline is feasible and safe in adult critically ill patients. Minerva Anestesiol. 2012;78(9):982-95.

26. Maury E, Vitry P, Galbois A, Ait-Oufella H, Baudel JL, Guidet B, Offenstadt G. Continuous insulin administration via complex central venous catheter 
infusion tubing is another risk factor for blood glucose imbalance. A retrospective study. Ann Intensive Care. 2012;2(1):16.

27. Yoo S, Lee HJ, Lee H, Ryu HG. Association between perioperative hyperglycemia or glucose variability and postoperative acute kidney injury after liver transplantation: a retrospective observational study. Anesth Analg. 2017;124(1):35-41.

28. Mita N, Kawahito S, Soga T, Takaishi K, Kitahata H, Matsuhisa M, Shimada M, Kinoshita H, Tsutsumi YM, Tanaka K. Strict blood glucose control by an artificial endocrine pancreas during hepatectomy may prevent postoperative acute kidney injury. J Artif Organs. 2017;20(1):76-83.

29. Sathishkumar S, Lai M, Picton P, Kheterpal S, Morris M, Shanks A, Ramachandran SK. Behavioral modification of intraoperative hyperglycemia management with a novel real-time audiovisual monitor. Anesthesiology. 2015;123(1):29-37.

30. Damiano ER, McKeon K, El-Khatib FH, Zheng H, Nathan DM, Russell SJ. A comparative effectiveness analysis of three continuous glucose monitors: the navigator, G4 platinum, and Enlite. J Diabetes Sci Technol. 2014;8(4): 699-708.

31. Subramaniam B, Lerner A, Novack V, Khabbaz K, Paryente-Wiesmann M, Hess P. Talmor D. Increased glycemic variability in patients with elevated preoperative $\mathrm{HbA1C}$ predicts adverse outcomes following coronary artery bypass grafting surgery. Anesth Analg. 2014;118(2):277-87.

32. Hirsch IB. Sliding scale insulin--time to stop sliding. JAMA. 2009;301(2):213-4.

33. Moghissi ES, Korytkowski MT, DiNardo M, Einhorn D, Hellman R, Hirsch IB, Inzucchi SE, Ismail-Beigi F, Kirkman MS, Umpierrez GE, et al. American Association of Clinical Endocrinologists and American Diabetes Association consensus statement on inpatient glycemic control. Diabetes Care. 2009; 32(6):1119-31.

34. Lee YY, Lin YM, Leu WJ, Wu MY, Tseng JH, Hsu MT, Tsai CS, Hsieh AT, Tam KW. Sliding-scale insulin used for blood glucose control: a meta-analysis of randomized controlled trials. Metabolism. 2015;64(9):1183-92.

35. Nair BG, Horibe M, Neradilek MB, Newman SF, Peterson GN. The effect of intraoperative blood glucose management on postoperative blood glucose levels in noncardiac surgery patients. Anesth Analg. 2016;122(3):893-902.

36. Nair BG, Grunzweig K, Peterson GN, Horibe M, Neradilek MB, Newman SF, Van Norman G, Schwid HA, Hao W, Hirsch IB, et al. Intraoperative blood glucose management: impact of a real-time decision support system on adherence to institutional protocol. J Clin Monit Comput. 2016:30(3):301-12.

37. Filho NO, Alves RL, Fernandes AT, Castro FS, Melo JR, Modolo NS. Association of increased morbidity with the occurrence of hyperglycemia in the immediate postoperative period after elective pediatric neurosurgery. J Neurosurg Pediatr. 2016;17(5):625-9.

38. Aljiffry M, Hassanain M, Schricker T, Shaheen M, Nouh T, Lattermann R, Salman A, Wykes L, Metrakos P. Effect of insulin therapy using hyperinsulinemic Normoglycemic clamp on inflammatory response in brain dead organ donors. Exp Clin Endocrinol Diabetes. 2016;124(5):318-23.

\section{Publisher's Note}

Springer Nature remains neutral with regard to jurisdictional claims in published maps and institutional affiliations.

Ready to submit your research? Choose BMC and benefit from:
- fast, convenient online submission
- thorough peer review by experienced researchers in your field
- rapid publication on acceptance
- support for research data, including large and complex data types
- gold Open Access which fosters wider collaboration and increased citations
- maximum visibility for your research: over 100M website views per year
At BMC, research is always in progress.
Learn more biomedcentral.com/submissions

